\title{
A Survey of Mosquito Species and Implication for Malaria Transmission in Abakaliki, Ebonyi State, Nigeria
}

\author{
${ }^{1}$ Odikamnoro, O. O; ${ }^{1}$ Uhuo, C. A; ${ }^{2}$ Ibiam, G.A. \\ ${ }^{I}$ Department Of Applied Biology, Ebonyi State University Abakaliki Ebonyi State. Nigeria. \\ ${ }^{2}$ Department of Medical Laboratory Sciences, Ebonyi State University, Abakaliki, Ebonyi State. Nigeria. \\ Correspondence Author: Department Of Applied Biology, Ebonyi State University Abakaliki Ebonyi State,
}

\begin{abstract}
A survey of major mosquito species was conducted in ten locations in Abakaliki using different mosquito tools. The study revealed that several mosquito species belonging to three genera (Aedes, Anopheles, and Culex) which are known vectors of different diseases (malaria, filariasis, yellow fever, dengue fever, encephalitis) where implicated. A total of 353 larvae and 477 adults were identified with three species of Aedes and 2 species each of anopheles and Culex. Anopheles gambiae was the most abundant species collected (34.6\%) followed by the complex Anopheles funestus (brucei) 27.5\%) Culex quinquefasciatus (23.55) Aedes tayolori $(1.2 \%)$. It was observed that the abundance of mosquito in the study area were as a result of general contributory factors such as water, shade, lack of predators and temperature. However, strategic measures such as environmental cleanliness, use of insecticide treated nets as well as public orientation and health education will assist the masses for effective control and prevention.
\end{abstract}

Keyword: Survey, mosquito, diseases, malaria, surveillance.

\section{Introduction}

Mosquitoes are insects belonging to the order diptera which are different for other flies due to the presence of a long piercing sucking mouthpart called the proboscis and scales on their wings. They have varying sizes not greater than $15 \mathrm{~mm}$ but weigh only $2-2.5 \mathrm{mg}$. They can fly at about 1.5 to $2.5 \mathrm{~km} / \mathrm{hr}$ with most nocturnal species. (Harbach and Knight, 1981). There are over 3000 different species of mosquitoes found ubiquitously in nearly every type of climatic region of the world from the arctic regions to the tropics, surviving severe winters or dry seasons of these regions. The dipterans are important as well as all other arthropods combined as far as vector-borne diseases are concerned. In this order, are the normal transmitters of malaria, African trypanosomiasis, onchocerciasis, loaisis leishmaniasis, yellow fever, lymphatic filariasis oroya fever, dengue fever, sand fly fever, myiasis, numerous encephalitis and other viral infections as well as a wide range of mechanically transmitted bacterial and viral diseases. Without the dipteran vectors, these diseases would probably entirely disappear. These insects abound in rural, peri- urban and even urban areas of developing countries where environmental conditions favour their breeding. Thus in these places vectors - borne diseases are transmitted to human populates unabated, (Harrison et al., 2001).

\section{Materials and Methods}

A survey for these dipteran vectors was carried out in a large peri-urban area of Abakaliki, Ten (10) areas of derived secondary vegetation were chosen at the outskirts of the town, which are characterized with thick vegetation covered with trees, grasses and forested plantation. In each of the locations, empty plastic containers which contain 3 liters of water kept in different designated sites based on human population, activities and vegetative cover. Other potential breeding sites like ponds, puddles and gutters found in some of these locations were also monitored regularly for mosquito larvae. The artificial containers as well as ponds, puddles and gutters were sampled using a standard mosquito larval dipper with extendable handle. Three scoops $(350 \mathrm{ml})$ of water were taken at each site. Larvae from those dips were extracted using dropper, and placed into glass vials with screw caps. Adult mosquitoes were trapped indoors in 10 locations at night and early morning using a mosquito bait installed with two (1.5v) batteries and light source that exposed their harboring site such as walls, cloths, curtains and other potential breeding sites. They were collected from the bait trap with thumb triceps and placed in a petridish with cover. Individual species was handled as much as possible so as not to remove scales and other identifiable characteristic features.

\section{Identification}

The identification of larvae was morphologically done according to Gillet (1972) and Gillies (1966) using a binocular light dissecting microscope according to their genera. The identification of adult mosquitoes was based on their characteristic colour and morphological features, according to Evans (1938) and Edward (1941). 
The Survey Of Mosquitoe Species And Implications For Malaria Transmission In Ebonyi State Preservation of larvae and adult

The mosquitoes were then fixed and preserved in x50 mixture of water and 70\% Isopropyl alcohol in glass vials.

\section{Results}

A total of 353 mosquito larvae belonging to three genera were collected and identified. Of this number, $153(43.4 \%)$ were from ponds, $65(18.4 \%)$ from gutters, 35 (9.9\%) from puddles, 34 (9.69\%) from plastic containers, $22(6.3 \%)$ from tin cans, $20(5.5 \%)$ from discarded tyres 14(3.9\%) from leaf axils of plantain and 10 (2.8\%) from bamboo stumps. The genus Anopheles were the most prevalent encountered in ponds and puddles, while Culex were more abundant in gutters and plastic containers, and the Aedes were more in tin cans and discarded tyres. The pooled group total abundance shows Anopheles 137 (44.5\%) followed by Culex 119 9(33.7\%) and Aedes $77(21.8 \%)$.

Table 1: The relative abundance of different mosquito larvae obtained in different location.

\begin{tabular}{|l|l|l|l|}
\hline Location & Aedes & Anopheles & Culex \\
\hline A1 & 5 & 7 & 10 \\
\hline A2 & 12 & 27 & 16 \\
\hline A3 & 10 & 17 & 13 \\
\hline A4 & 6 & 8 & 6 \\
\hline A5 & 9 & 12 & 18 \\
\hline A6 & 13 & 30 & 20 \\
\hline A7 & 8 & 20 & 12 \\
\hline A8 & 8 & 16 & 11 \\
\hline A9 & 9 & 12 & 18 \\
\hline A10 & 6 & 19 & 13 \\
\hline Total & 77 & 157 & 119 \\
\hline
\end{tabular}

Table 2: The abundance of different adult mosquito species obtained in doors.

\begin{tabular}{|l|l|l|l|l|l|l|l|}
\hline Location & $\begin{array}{l}\text { Anopheles } \\
\text { garnbiae }\end{array}$ & $\begin{array}{l}\text { Anophele } \\
\text { sfunestus }\end{array}$ & $\begin{array}{l}\text { Aedes } \\
\text { aegypti }\end{array}$ & $\begin{array}{l}\text { Aedes } \\
\text { albopictus }\end{array}$ & $\begin{array}{l}\text { Aedes } \\
\text { taylori }\end{array}$ & $\begin{array}{l}\text { Culex } \\
\text { annulioris }\end{array}$ & $\begin{array}{l}\text { Culex } \\
\text { Quinquefasciatus }\end{array}$ \\
\hline A1 & 14 & 10 & - & - & - & - & 10 \\
\hline A2 & 26 & 20 & 2 & 7 & 8 & 4 & 19 \\
\hline A3 & 11 & 15 & - & - & 3 & - & 11 \\
\hline A4 & 19 & 13 & - & - & 6 & - & 8 \\
\hline A5 & 9 & 5 & - & - & - & - & 12 \\
\hline A6 & 30 & 24 & 3 & 10 & 12 & 5 & 25 \\
\hline A7 & 10 & 6 & - & - & - & - & 9 \\
\hline A8 & 16 & 12 & - & - & - & - & 5 \\
\hline A9 & 18 & 11 & - & - & 4 & & - \\
\hline A10 & 12 & 14 & - & - & - & 3 & 6 \\
\hline & 165 & 130 & 5 & 17 & 33 & 15 & 112 \\
\hline
\end{tabular}

V. Discussion

The survey on mosquito species and its implication showed that there is a high relative abundance of adult and larvae of different species of mosquitoes existing in the peri- urban areas of Abakaliki. In ten locations sampled, a total of 353 larvae and 477 adult mosquitoes were collected and identified. the survey revealed that the most common species of abundance were Anophelese garnbiae (34.6\%), Anopheles funestus (27.5\%). This is in conformity with the study of Allan and Edman, (1989) who recorded high prevalence of Anopheles gambiae and Anopheles funestus collected with CDC high trap in Eldoret. Culex quinquefasciatus was another common species which was also found substantially in the studied locations, comprising roughly $(23.5 \%)$ of the entire mosquito species collected. This is also related to the findings by Weinstein, (1997) and Bequaet, (2000). who showed high prevalence in Kampuchea, Phnompenh Portland than in Netroun lake in Egypt.

Culex annulioris was also collected in small number accounting for $(3.2 \%)$ which could be that seasonal variations affected the abundance of other species like the Aedes species. These Culex species are the potential vectors of filariasis, encephalitis and other diseases. Service,(1993) consequently revealed same findings with Aedes species of Aedes taylori, Aedes albopictus, and Aedes egypti found in related numbers with 6.9\%, 3.6\%, and $1.2 \%$ respectively. Aedes species seems to appear in small numbers but occurred regularly at all times. Aedes species poses an important public health importance as it is the major cause of filariasis, yellow fever, 
dengue fever and other various diseases, thus affecting both animals and human population. Anopheles is the vectors in abundant breeding sites which pose risk of malaria infection, ensuring disease endemicity in some areas. Malaria is one of the most common causes of morbidity and mortality in sub-Saharan African with an estimated figure of 28 million people who die of malaria, these vectors are also the responsible agents of filariasis and arboviruses.

The seasonal pattern of prevalence varies significantly but here, it was directly favoured by the availability of stagnant water, shade, lack of predators and temperatures which seem to be the primary cause of prevalence of these mosquito species while any change that affect these factors during dry and wet seasons probably affects mosquito cycle, there by causing decrease in their numbers.

\section{Conclusion}

Mosquitoes are not only considered as a nuisance but also vectors responsible for the transmission of several disease agents in humans and animals. However, it is necessary that control measure is encouraged to reduce the risk of these diseases as well as reduce the stress burden on both domesticated animals and humans. It was discovered that the most prevalent area of adult mosquitoes in this research were locations that had high human population and the availability of natural and man-made mosquito breeding sites. It was also discovered that most of the species larva shared habitats like the larvae of Aedes recovered from one container and no larvae were found in containers that were not shaded from the sun. Even blade of grasses in unsheltered buckets, puddles, tyre holes and polythene bags that contain water. Due to the presence of this conducive and adaptive environment, mosquitoes are able to breed in large numbers thereby progressively propagating the transmission of diseases.

\section{References}

[1]. Allan, S. A and Edman, J. D. (1989). Studies on breeding sites of mosquitoe species (Dipteran culicidae) in Eldoret. Annual Review of Entomology, 32: 297-316.

[2]. Bequaert, J. (2000). The re- emergence of Quinquefasciatus in Arizona. Bulletin of Brooklyn. Entomological Society 14: $157-158$.

[3]. Edward, R. A. (1941). A Catalogue of African Mosquitoes (Diptera culicidae) (2 ${ }^{\text {nd }}$ ed) McGraw Hill, London. 425 pp.

[4]. Gillet, J. D. (1972). Common African Mosquitoes and their medical importance. William Heineman, Medical Book Ltd London, 353 pp.

[5]. Gillies, M. T. (1986). Mosquitoes of the South Saharan African (Anophelin) ( $3^{\text {rd }}$ ed) Weidenfeld and Nicolsor London 574pp.

[6]. Harbachs, R. E. and Knight, K. L (1981). Mosquitoes systematic. Glossary of mosquito Anatomy, 13: $201-217$.

[7]. Harrison, B. A. Tunell, M. J., O' Guin, M. L Sardelis, M. R., and Jonusr D. J. (2001). Preparing for west nile virus and multidirectional surveillance and control. Annals of the Entomological Society of American 94: 574-582.

[8]. Service, M. W. (1993) Mosquitoes (Gulicidea), Lanes R. P. and Cross key R. W (Editors) Medical insects and Arachnids. Chapman and Hall, London. 238pp.

[9]. Weinsten, P. J, Laired, M. D, and Brome, G (1997) Pest Management Strategy for exotic mosquitoes of public health significance. Journal of Medical Entomology 19: 189-195. 